\title{
Multiformity of Photoelectron Storages in Functionalized Carbon \\ Nitrides Enabling Reversible and Adaptable Colorimetric Sensing
}

Dan Han, ${ }^{\mathrm{a}}$ Hong Yang, ${ }^{\mathrm{a}}$ Zhixin Zhou, ${ }^{\mathrm{a}}$ Kaiqing Wu, ${ }^{\mathrm{a}}$ Jin Ma, ${ }^{\mathrm{a}}$ Yanfeng Fang, ${ }^{\mathrm{a}}$ Qing Hong, ${ }^{a}$ Guangcheng Xi, ${ }^{b}$ Songqin Liu, ${ }^{a}$ Yanfei Shen, ${ }^{a}$ Yuanjian Zhang ${ }^{a *}$

a Jiangsu Engineering Laboratory of Smart Carbon-Rich Materials and Device, Jiangsu Province Hi-Tech Key Laboratory for Bio-Medical Research, State Key Laboratory of Bioelectronics, School of Chemistry and Chemical Engineering, Medical School, Southeast University, Nanjing 211189, China, Email: Yuanjian.Zhang@seu.edu.cn b Institute of Industrial and Consumer Product Safety, Chinese Academy of Inspection and Quarantine, Beijing 100176, P. R. China 


\begin{abstract}
Colorimetric sensing has been widely used for centuries across diverse fields, thanks to easy operation with no electricity and uncompromised high sensitivity. However, the limited number of chromogenic systems hampers its broader applications. Here, we reported that carbon nitride $(\mathrm{CN})$, the raw materials-abundant and cheap semiconductors with photoelectron storage capability, can be developed as a new chromogenic platform for colorimetric sensing. Beyond most photoelectron storage materials that only demonstrated blue color in the excited state, $\mathrm{CN}$ could also exhibit brown color by terminal group functionalization. The experiments and DFT theoretical calculation revealed the origin of the unusual two types of color switches. Cyano and carbonyl terminal groups in $\mathrm{CN}$ elongated the centroids distance of electron/hole and stabilized the excited states through a physical and electrochemical pathway, respectively; meanwhile, the counter cations strengthened these processes. As a result, the $\mathrm{CN}$-derived colorimetric $\mathrm{O}_{2}$ sensors demonstrated excellent reversibility in recycling hundreds of times for detection, and exhibited adaptable limit of detection and linear detection range, which was superior to commercial $\mathrm{O}_{2}$ sensors, especially for complex systems with broad variable concentrations.
\end{abstract}

Keywords: colorimetric sensing, carbon nitrides, photoelectron storage, reversibility, functional groups. 
Colorimetric sensors, accompanied by color switches visible to naked eyes, have attracted significant attention in chemical and biological fields during the past decades, owing to easy operation without electricity meanwhile maintaining high sensitivity. ${ }^{1-2}$ For instance, $\mathrm{pH}$ test papers are the most popular colorimetric sensors using dissociation or acquisition of protons in organic indictors. ${ }^{3}$ More complicated catalytic oxidation of chromogenic substrates, such as 3,3',5,5' -tetramethylbenzidine (TMB), ${ }^{4-5}$ into colored products have also been developed for well-known enzyme-linked immunosorbent assay (ELISA) ${ }^{6-7}$. Apart from chemical approaches, physical processes, such as local surface plasmon resonances in which the collective oscillation of electrons occurs at the metallic interface, are explored for colorimetric sensing with ultrahigh sensitivity. ${ }^{8-}$ ${ }^{9}$ Nonetheless, in contrast to numerous dyes, only a minimal number of chromogenic systems have been reported so far for colorimetric sensors. ${ }^{10-11}$ One can imagine that developing new mechanism-based chromogenic system with multiformity and high reversibility is of great interest for more demanding future applications. ${ }^{12}$

Photoelectron storing materials, including conventional metal oxides (e.g., $\mathrm{WO}_{3}{ }^{13-14}$, $\mathrm{TiO}_{2}{ }^{15-17}$, and $\mathrm{ZnO}^{18}$ ) and recent polymeric carbon nitrides $(\mathrm{CN}),{ }^{19-20}$ can accumulate electrons upon light excitation. Interestingly, all their long-lived excited states generally demonstrated a unique blue color, ${ }^{21-23}$ indicative of a new type of chromogenic mechanism. Compared to previous chromogenic principles, ${ }^{24-25}$ metastable charging/discharging of photoelectrons do not bring any permanent molecular or geometric structure transformations, making the color switch high reversibility. However, the modulation of such intriguing photoelectron storage towards multiple colors and the associated applicability for further development of colorimetric sensors have been rarely studied.

Here, we report a CN-based photoelectron accumulation platform for colorimetric sensing. Interestingly, beyond the typical blue color for most photoelectron storing materials in excited states, ${ }^{26-27}$ brown color was realized by modulating the terminal functional moieties on $\mathrm{CN}$. Comprehensive structure characterization and DFT calculations revealed the critical roles of variable functional groups and counter cations 
for $\mathrm{CN}$ in photoelectron accumulation, revealing a unique physical and chemical mixed mechanism. As a result, taking detection of $\mathrm{O}_{2}$ as an example, the $\mathrm{CN}$-derived colorimetric sensors demonstrated excellent reversibility in recycling hundreds of times and adaptable limit of detection and linear detection range, holding significant advantages to accommodate varying application requirements, especially for complex systems.
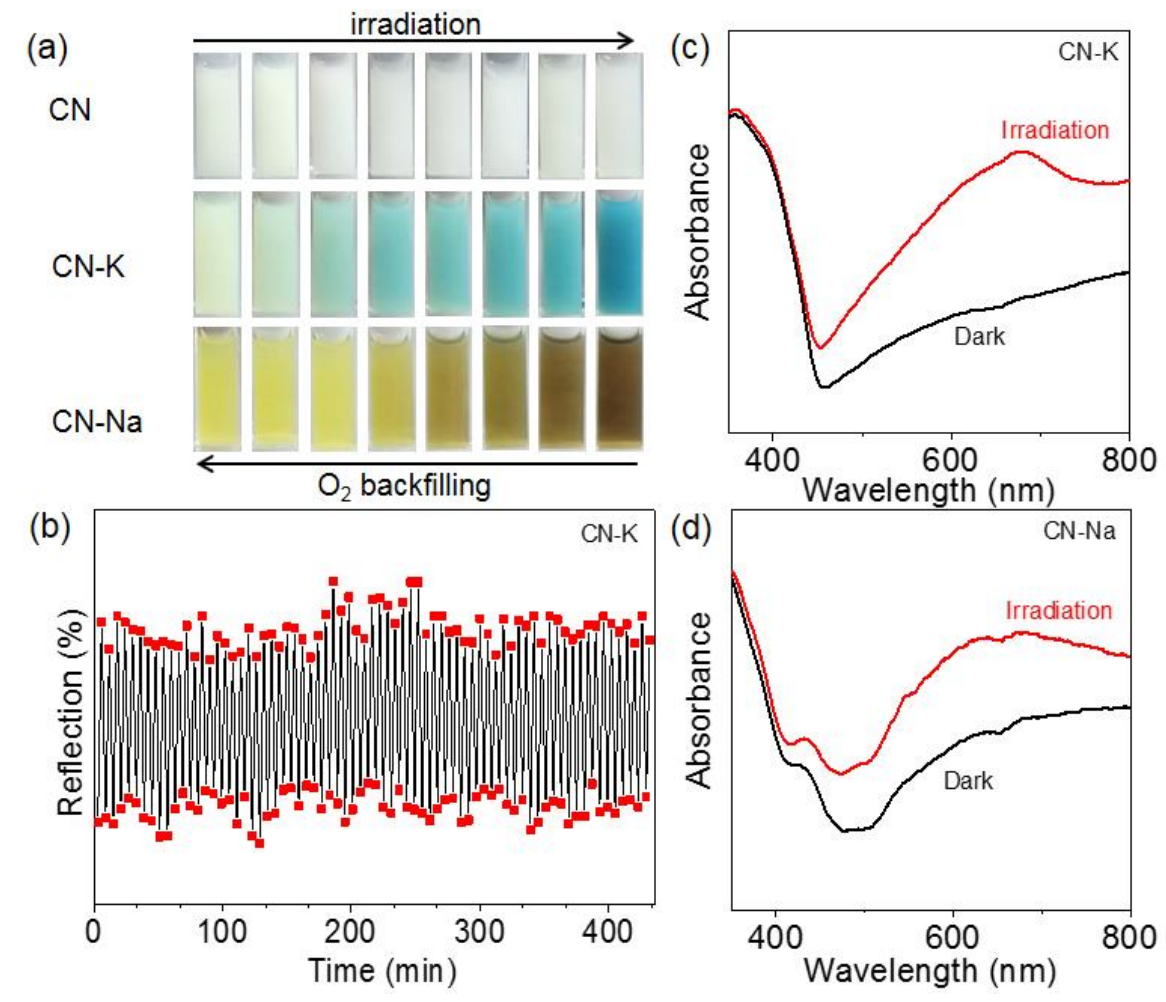

Figure 1. Reversible color switch based on varied $\mathrm{CN}$ via photoelectron accumulation. (a) Photographs of color evolution of $\mathrm{CN}, \mathrm{CN}-\mathrm{K}$, and $\mathrm{CN}-\mathrm{Na}$ suspensions under the irradiation of light and $\mathrm{O}_{2}$ backfilling. (b) Reversible color switching between pale-yellow and dark blue of $\mathrm{CN}-\mathrm{K}$ suspension after irradiation and $\mathrm{O}_{2}$ backfilling. UV-vis absorption spectra of $\mathrm{CN}-\mathrm{K}$ (c) and $\mathrm{CN}-\mathrm{Na}$ suspension (d) before and after irradiation.

To understand the intrinsic structures that determine the color of carbon nitrides upon irradiation, conventional pristine $\mathrm{CN}$, potassium-doped $\mathrm{CN}(\mathrm{CN}-\mathrm{K})$ and sodium-doped $\mathrm{CN}(\mathrm{CN}-\mathrm{Na})$ were prepared by a two-step condensation method (see details in Supporting Information). The suspension of different carbon nitrides in the presence of 
triethanolamine (TEA or TEOA) sacrificial electron donors was purged with $\mathrm{N}_{2}$ to obtain an $\mathrm{O}_{2}$-free environment. ${ }^{28}$ As shown in Figure 1a, the original color of the $\mathrm{CN}$ K suspension was pale yellow. The blue color evolution was observed after irradiation, while the discoloration occurred when exposed to air. This color switch was highly reversible upon continuous cycling (Figure 1b). Interestingly, the CN-Na suspension demonstrated a unique switch between yellow and brown (Figure 1a) with high reversibility (Figure S3). In contrast, the pristine $\mathrm{CN}$ suspension did not show any color change under the same conditions. ${ }^{29-31}$ The detailed absorption spectra in Figure 1c showed the blue suspension exhibited a broad tail from 500 to $800 \mathrm{~nm}$ apart from the primary absorption at $400 \mathrm{~nm}$, consistent with the previous reports. ${ }^{15}$ An enhancement across the broad range of 400-800 nm was observed in the absorption spectrum of $\mathrm{CN}$ $\mathrm{Na}$ after irradiation, enabling the color switch from yellow to brown (Figure 1d). However, CN did not have a new UV-vis absorption peak after irradiation, accompanying no color change (Figure S7).
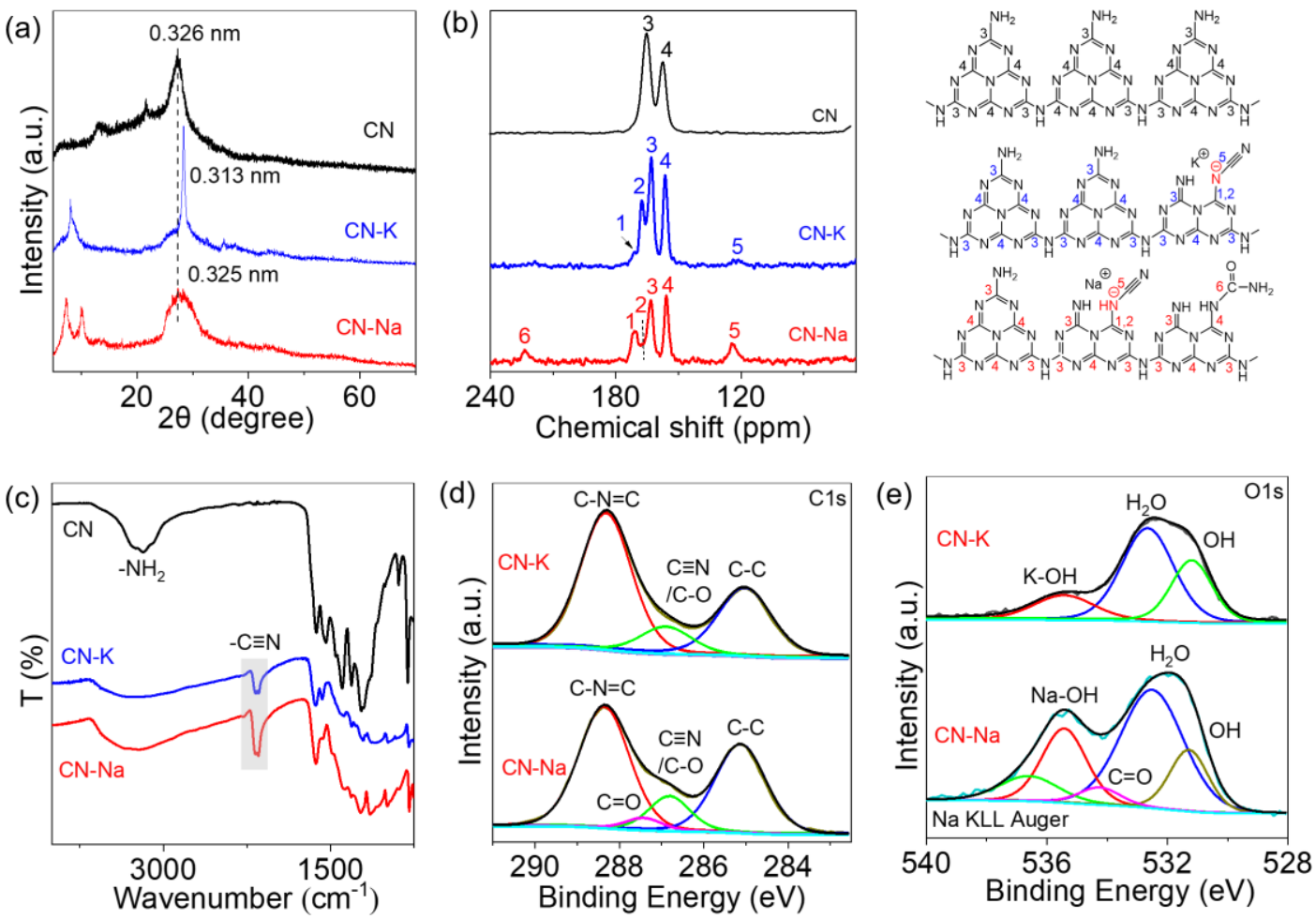

Figure 2. Structure characterization of functionalized CN. (a) XRD patterns, (b) Solid-state ${ }^{13} \mathrm{C}$ MAS NMR spectra, and (c) FTIR spectra of CN, CN-K, and CN-Na. (d) C1s XPS spectra and (e) O1s XPS spectra of CN-K and CN-Na. 
To reveal why $\mathrm{CN}-\mathrm{K}$ suspension was able to generate blue color but $\mathrm{CN}-\mathrm{Na}$ displayed brown color, the texture of the as-prepared $\mathrm{CN}-\mathrm{K}$ and $\mathrm{CN}-\mathrm{Na}$ was firstly investigated. As shown in Figure 2a, the XRD pattern of the conventional CN demonstrated two major diffraction peaks at $13.1^{\circ}$ and $27.3^{\circ}$, which can be assigned to the (100) and (002) crystal planes of graphitic materials, representing in-plane packing and interfacial stacking of aromatic segments, respectively. ${ }^{32}$ Different from pristine $\mathrm{CN}$, the XRD features of $\mathrm{CN}-\mathrm{K}$ and $\mathrm{CN}-\mathrm{Na}$ evidenced structural changes. The diffraction peak of (002) of CN-Na was sharper and slightly shifted relative to $\mathrm{CN}$ from $27.3^{\circ}$ to $28.3^{\circ}$, suggesting enhanced crystallinity and decreased interlayer distances from 0.326 to $0.313 \mathrm{~nm}$. It could be attributed to enhanced interactions between conjugated aromatic layers when $\mathrm{K}$ atoms existed in the $\mathrm{CN}$ interlayer, which was supposed to benefit the transfer and separation of charge carriers. ${ }^{33-34}$ Moreover, the signal of (100) at $13^{\circ}$ disappeared accompanied by a low angle reflection was observed at $2 \theta$ of $8.1^{\circ}$. It suggested that the original in-plane structure was partially changed. Similarly, the lattice fringes, corresponding to an interval of $10 \AA$ and $3.1 \AA$ within the layer planes and interlamination, were observed in the high-resolution TEM image. The fitted fast Fourier transformation (FFT) image from large crystallites (Figure S1d, inset) consisted of the XRD result (Figure 2a). ${ }^{35}$ In contrast, a broad and weak peak centered at $27^{\circ}$ (range from $26.5^{\circ}$ to $28.4^{\circ}$ ) was revealed for $\mathrm{CN}-\mathrm{Na}$, indicative of the disorder in interlayer stacking of aromatic structure and weaker crystallinity, which were possibly desirable to introduce more surface states or defects compared with CN-K.

To probe more insight into the chemical structure, solid-state ${ }^{13} \mathrm{C}$ magic angle spinning nuclear magnetic resonance (MAS NMR) spectroscopy, Fourier transform infrared (FT-IR) spectroscopy and X-ray photoelectron spectroscopy (XPS) measurements were carried out. As shown in Figure 2b, the two strong peaks for heptazine units at about 164.8 and $156.6 \mathrm{ppm}$ were observed, corresponding to $\mathrm{C}_{3} \mathrm{~N}$ (3) and $\mathrm{C}_{2 \mathrm{~N}-\mathrm{NHx}}(4)$ in all carbon nitride samples, respectively. ${ }^{36}$ Consistently, characteristic peaks located at 810 and $1000-1700 \mathrm{~cm}^{-1}$, attributed to the plane bending of the 
heptazine units ring and the stretching and bending modes of conjugated $\mathrm{CN}$ heterocycles were also all observed in the FT-IR spectra (Figure 2c). ${ }^{37}$ Notably, three new peaks at $122.4(\mathbf{C 5}), 168(\mathbf{C 2})$, and $171.8(\mathbf{C 1})$ ppm appeared in the MAS NMR spectrum of $\mathrm{CN}-\mathrm{K} .{ }^{38}$ These typical peaks were assigned to the carbon atoms in $\mathrm{C} \equiv \mathrm{N}$ and the neighbor carbon atoms of $\mathrm{C} \equiv \mathrm{N}$. This important structure could also be evidenced by the FT-IR spectrum in the asymmetric stretching vibration ranging from 2150 to $2178 \mathrm{~cm}^{-1}$ (Figure $2 \mathrm{c}$ ) and the $\mathrm{C} 1 \mathrm{~s}$ spectrum of $\mathrm{CN}-\mathrm{K}$ centered at $286.8 \mathrm{eV}$ in the XPS survey spectra (Figure 2d). ${ }^{39}$ More interestingly, the ${ }^{13} \mathrm{C}$ NMR of CN-Na showed a new peak at $220 \mathrm{ppm}(\mathbf{C 6})$, which was assigned to the carbon atom from the carbonyl $(\mathrm{C}=\mathrm{O})$ of $\mathrm{CN}-\mathrm{Na},{ }^{40-41}$ consistent with the XPS O1s spectrum at $534.2 \mathrm{eV}$ (Figure 2e) and XPS C1s spectrum at $287.4 \mathrm{eV} \cdot{ }^{42-43}$ The $\mathrm{C}=\mathrm{O}$ stretching vibrations in the FT-IR spectrum of $\mathrm{CN}-\mathrm{Na}$ were overlapped but still demonstrated a relatively a stronger peak at around $1650 \mathrm{~cm}^{-1} .{ }^{44}$ Thus, compared to $\mathrm{CN}-\mathrm{K}, \mathrm{CN}-\mathrm{Na}$ not only had $\mathrm{C} \equiv \mathrm{N}$ terminals but also functionalized with $\mathrm{C}=\mathrm{O}$ groups.

The composition of different carbon nitrides was quantitively evaluated using combustion elemental analysis and inductively coupled plasma mass spectroscopy (ICP-MS, Table S1). It was found that the atom ratios of C/N in CN-K (0.693) and CN$\mathrm{Na}(0.696)$ were slightly altered, compared to pristine $\mathrm{CN}(0.679)$, indicating the carbon nitride framework mainly was retained after the doping. ${ }^{45}$ Nonetheless, an evident increase of $\mathrm{O}$ was observed for $\mathrm{CN}-\mathrm{Na}$, which possibly originated from the absorbed water of $\mathrm{NaI}^{46}$ A control experiment by vacuum drying $\mathrm{NaI}$ and melon before the full condensation was undertaken to verify this assumption. It was found that the ${ }^{13} \mathrm{C}$ NMR signal at about $220 \mathrm{ppm}$ for $\mathrm{C}=\mathrm{O}$ became weaker (Figure S8a), and the brown color after illumination was also lighter (Figure S8b), both of which were in line with the expectations. The content of $\mathrm{K}$ and $\mathrm{Na}$ in $\mathrm{CN}-\mathrm{K}$ and $\mathrm{CN}-\mathrm{Na}$ were $4.31 \mathrm{wt} \%$ and 4.33 wt $\%$, respectively, verifying that the $\mathrm{K}^{+}$or $\mathrm{Na}^{+}$were introduced into the heptazinebased melon framework of carbon nitrides. ${ }^{47}$ It was also proved by two new peaks at $979 \mathrm{~cm}^{-1}$ and $1143 \mathrm{~cm}^{-1}$ in the FT-IR spectrum in Figure 2c, corresponding to symmetric and asymmetric vibrations of $\mathrm{NC}_{2}$ bonds of metal- $\mathrm{NC}_{2}$ groups. ${ }^{48}$ Therefore, 
$\mathrm{K}^{+}$and $\mathrm{C} \equiv \mathrm{N}$ were cooperated into tri-s-triazine units of $\mathrm{CN}-\mathrm{K}$, while $\mathrm{Na}^{+}, \mathrm{C} \equiv \mathrm{N}$, and $\mathrm{C}=\mathrm{O}$ were modified on the $\mathrm{CN}-\mathrm{Na}$.

As known, structural control of carbon nitride by introducing functional groups or "defects" had been the efficient pathway to tune electronic band structure and charge carrier transfer, which can improve optoelectronic or photocatalysis properties. ${ }^{49}$ Figure S2a demonstrated that the intrinsic absorption edge of $\mathrm{CN}-\mathrm{K}$ had an obvious red-shift concerning $\mathrm{CN}$, associated with a decreased bandgap of ca. $0.1 \mathrm{eV}$; in contrast, $\mathrm{CN}-\mathrm{Na}$ did not display such a significant change. To better understand the charge separation processes, photoluminescence (PL) and electron paramagnetic resonance (EPR) spectroscopy measurements were performed. It is known that PL is frequently used to probe the charge separation and recombination, owing to photo-induced electron-hole pairs recombining and accompanied by emitting light. ${ }^{50}$ Compared with $\mathrm{CN}$, the PL peak intensity of $\mathrm{CN}-\mathrm{K}$ and $\mathrm{CN}-\mathrm{Na}$ exhibited a significant reduction (Figure S2c), elucidating that radiative charge recombination was less probable. ${ }^{51-52}$ This was further evidenced by the gradually decreased lifetimes of charge carriers determined by the time-resolved fluorescence decay spectra, as shown in Figure S2d. ${ }^{53-}$ ${ }^{54}$ Apart from the optical measurements, another noticeable change was in the electronic properties of samples, as demonstrated by the solid-state ESR spectra measured at room temperature (Figure S2e). All samples exhibited a single Lorentzian peak at g value of 2.003, which is originated from the unpaired electron of sp2-carbon the aromatic rings within $\pi$-conjugated heterocycle, but the peak intensity of $\mathrm{CN}-\mathrm{K}$ and $\mathrm{CN}-\mathrm{Na}$ powders slightly increased, compared to $\mathrm{CN}$. It was probably due to the delocalization of $\pi$ electrons in the conjugated system, contributed by $\mathrm{C} \equiv \mathrm{N}$ and $\mathrm{C}=\mathrm{O}$ moieties, generating more unpaired electrons. ${ }^{55}$ 
(a)

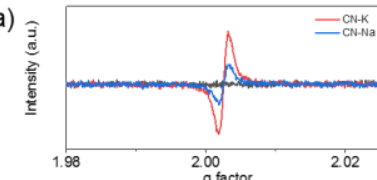

(b)
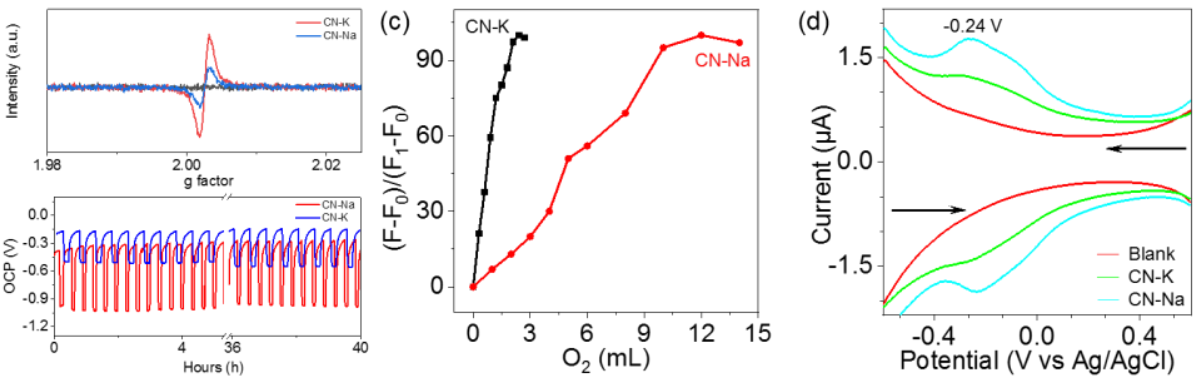

(e)
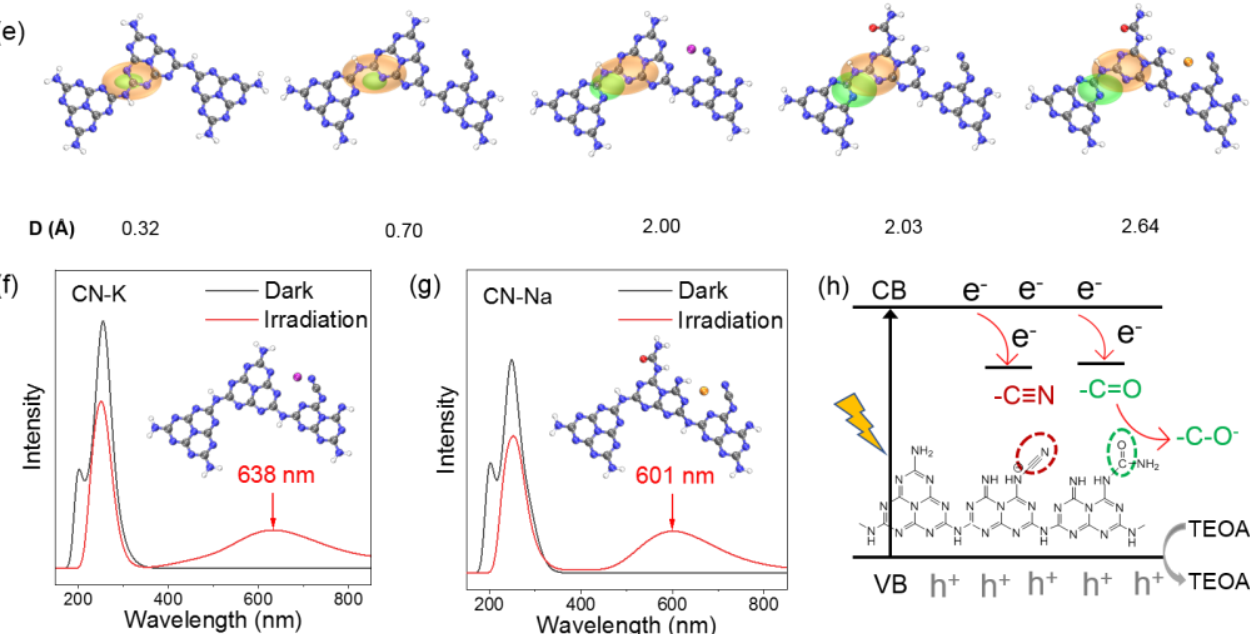

0.70

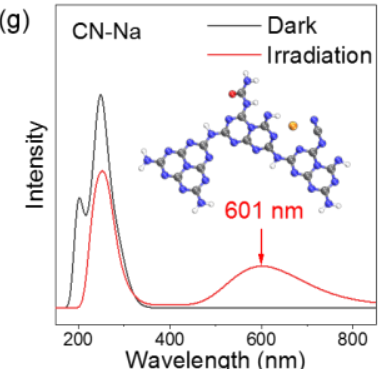

2.03

2.64

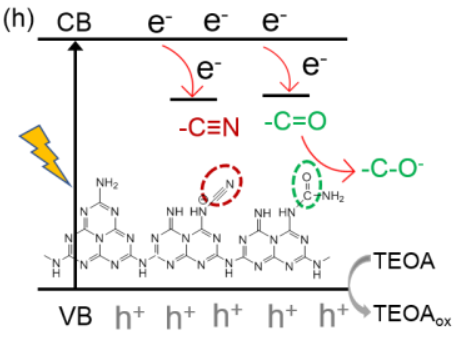

Figure 3. Chromogenic mechanism of $\mathrm{CN}-\mathrm{K} / \mathrm{-Na}$ under photoelectron accumulation. (a) ESR spectra of $\mathrm{CN}-\mathrm{K}$ and $\mathrm{CN}-\mathrm{Na}$ suspension after irradiation. (b) OCP measurements of CN-K and CN-Na suspension under continuous chopped light. (c) Recovery efficiency of CN-K and $\mathrm{CN}-\mathrm{Na}$ suspension given consuming oxygen after irradiation. (d) Differential pulse voltammograms (DPV) of bare electrode, CN-K, and CN-Na. (e) Calculated smooth description of electron (orange isosurface) and hole (blue isosurface) spatial population distribution in different carbon nitrides for the most vital electronic excited states between 600-700 nm. Gray coloring indicates carbon atoms, blue indicates nitrogen, white indicates hydrogen, purple indicates $\mathrm{K}$, red indicates $\mathrm{O}$, and orange indicates $\mathrm{Na}$. Calculated absorption spectra of (f) $\mathrm{CN}-\mathrm{K}$ and (g) $\mathrm{CN}-\mathrm{Na}$ before and after irradiation. (h) Proposed color-switch mechanism for photoelectron storage by $\mathrm{CN}-\mathrm{K}$ and $\mathrm{CN}-\mathrm{Na}$.

To further verify the properties of electrons stored in $\mathrm{CN}-\mathrm{K}$ and $\mathrm{CN}-\mathrm{Na}$, ESR spectroscopy was used to determine the nature of the trapped electron species in the blue suspension in the presence of TEOA as sacrificial electron donor under $\mathrm{O}_{2}$-free 
conditions after irradiation. The blue suspension showed a distinctly enhanced ESR signal with a $g$ value of 2.0021 near the free electrons, which revealed the characters of the stored electrons (Figure 3a). ${ }^{21}$ It was also the case for the brown color system of $\mathrm{CN}-\mathrm{Na}$ where the same $\mathrm{g}$ value of 2.0021. The photoelectrochemical measurements were also performed to quantitively evaluate the highly reductive of electrons stored in $\mathrm{CN}-\mathrm{K}$ and $\mathrm{CN}-\mathrm{Na}$. Figure 3b showed the open circuit potential (OCP) of $\mathrm{CN}-\mathrm{K}$ photoelectrode altered from ca. $-250 \mathrm{mV}$ (light on in inert atmosphere) to $-1080 \mathrm{mV}$ (light off with $\mathrm{O}_{2}$ backfilled). Such an apparent OCP switch (ca. $0.8 \mathrm{~V}$ ) could be cycled over 100 times, lasting more than 40 hours. Note that the attenuation was partially attributed to detachment of $\mathrm{CN}-\mathrm{K}$ film from FTO, demonstrating that the photoelectron storage in carbon nitrides was highly reversible and stable. ${ }^{19,56-57}$

In contrast, the reversible OCP change of $\mathrm{CN}-\mathrm{Na}$ was only ca. $0.4 \mathrm{~V}$ under the same measurement condition (Figure 3b). Nonetheless, CN-Na demonstrated a higher consumption of backfilled oxygen than $\mathrm{CN}-\mathrm{K}$ (Figure 3c). It suggested another type of electron storage pathway in $\mathrm{CN}-\mathrm{Na}$, except for the well-known capacitor-like photoelectron charging for blue $\mathrm{CN}-\mathrm{K}$. In principle, chemical redox reactions were probably like that for secondary batteries. Differential pulse voltammetry (DPV) curves of all carbon nitride samples were measured to support this assumption. Figure 3d showed that the $\mathrm{CN}-\mathrm{Na}$ electrode demonstrated a more profound reduction/oxidation peaks at ca. $0.2 \mathrm{~V}$ than pristine $\mathrm{CN}$ and $\mathrm{CN}-\mathrm{K}$ electrode in a deoxygenated electrolyte solution. These redox waves were often associated with the reduction and oxidation of $\mathrm{C}=\mathrm{O}$ groups. Considering the amount of $\mathrm{C}=\mathrm{O}$ in $\mathrm{CN}-\mathrm{Na}$ was much larger than that in the other two carbon nitrides, the more substantial photoelectron storage capacity of $\mathrm{CN}-\mathrm{Na}$ could be ascribed to both physical and chemical charging processes, enabled by the dual functional groups.

These speculations were further supported by the DFT calculation of the electron/hole population during excitation and the absorption spectra of $\mathrm{CN}-\mathrm{K}$ and $\mathrm{CN}$ $\mathrm{Na}$ (Figure 3e-g). For this, five ideal representative structures were compared. Briefly, pristine $\mathrm{CN}$ (1) was constructed only using heptazine units. An incompletely condensed 
heptazine ring with a cyano end-group was introduced in $\mathrm{CN}-\mathrm{K}$ (3) with negative charges stabilized by $\mathrm{K}^{+}$. Similarly, $\mathrm{CN}-\mathrm{Na}$ (5) was built by adding an amide group with $\mathrm{Na}^{+}$as the counterions. To understand the role of metal ions, 2 and 4 without $\mathrm{K}^{+}$ and $\mathrm{Na}^{+}$were also explored as controls for $\mathbf{3}$ and $\mathbf{5}$, respectively. For pristine $\mathrm{CN}$, the symmetrical structure made the overall polarity zero, with no significant difference in electron distribution. When it was excited upon irradiation, the centroids distance of electron and hole was only $0.32 \AA$, making the electron-hole recombine rapidly. Interestingly, as shown in $\mathbf{2}$, the asymmetric structure endowed the centroids distance of electron and hole increase to $0.70 \AA$. After binding $\mathrm{K}^{+}$, the attraction between metal ions and electrons was enhanced, further boosting the centroids distance of electron and hole to $2.03 \AA$ A. Such significant spatial separation of electron and hole would inhibit the recombination and produce the long lifetime of the charge-separated pair, which explained the stable color development of $\mathrm{CN}-\mathrm{K}$ after irradiation, while bulk $\mathrm{CN}$ not. The centroids distances of electron and hole in $\mathbf{5}$ was even larger $(2.64 \AA)$, comparable to the diameter of the triazine ring, which may be ascribed to the more reactive polar $\mathrm{C}=\mathrm{O}$ group

To obtain more insights into different colors, the absorption spectra of $\mathrm{CN}-\mathrm{K}$ and $\mathrm{CN}-\mathrm{Na}$ before and after irradiation were further calculated. Before irradiation, the molecule was electrically neutral, and there were no unpaired electrons. After irradiation, $\mathrm{CN}-\mathrm{K}$ and $\mathrm{CN}-\mathrm{Na}$ underwent electron-hole separation, followed by accepting electrons from sacrificial TEOA, in which metal ions stabilized the switched doublet state. Figure 3f showed the stable structure of $\mathrm{CN}-\mathrm{Na}$ after irradiation could absorb more visible light between 400-800 $\mathrm{nm}$ compared to that before irradiation, with the most pronounced absorption peak at $601 \mathrm{~nm}$. While for $\mathrm{CN}-\mathrm{K}$, the position of the absorption peak was red-shifted to $638 \mathrm{~nm}$ (Figure $3 \mathrm{~g}$ ), well consistent with the experimental observation (Figure 1c and d). Considering the stabilizing effect of metal ions on carbon nitride, the binding sites were not limited to the structure in Figure $\mathbf{3 g}$ \& 3h, but they demonstrated similar trends in influencing the absorption spectra (Figure S9). 
At this point, the possible color-switch mechanism for photoelectron storage in $\mathrm{CN}$ was proposed (Figure 3h). Contrast with pristine CN (Figure S7a), the excited electrons in the conduction band $(\mathrm{CB})$ of $\mathrm{CN}-\mathrm{K}$ would transfer to the $\mathrm{C} \equiv \mathrm{N}$ groupderived state upon irradiation with TEOA as a hole quencher. $\mathrm{CN}-\mathrm{K}$ had an improved absorption in the visible light region centered approximately at $640 \mathrm{~nm}$, demonstrating the characteristic blue color like well-known $\mathrm{TiO}_{2}$ (Figure S7b). Alternatively, partially excited electrons in $\mathrm{CB}$ of $\mathrm{CN}-\mathrm{Na}$ transferred to the $\mathrm{C}=\mathrm{O}$ group-derived state, a redox reaction rather than physical electron accumulation, presumably lowering the OCP but enhancing the photoelectron storage capacity. ${ }^{28,58}$ Such an additional state would enable more absorption in the visible light region centered approximately at 600 $\mathrm{nm}$, finally endowing a brown color.
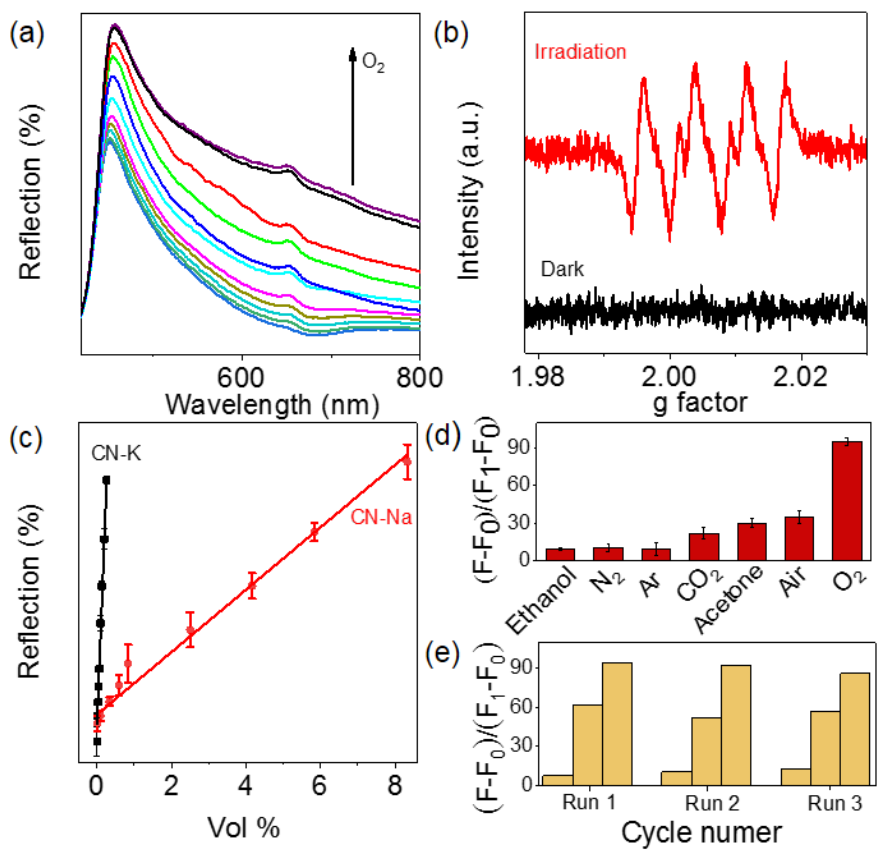

Figure 4. Colorimetric sensing of $\mathrm{O}_{2}$ using $\mathrm{CN}$-based photoelectron accumulation platform. (a) Reflection spectra in the presence of different $\mathrm{O}_{2}$ fractions (\%). (b) ESR spectra of $\mathrm{CN}-\mathrm{K}$ with DMPO in methanol for detecting superoxide radical $\left(\mathrm{O}_{2} \bullet-\right)$. (c) Calibration curves of $\mathrm{CN}-\mathrm{K}$ and $\mathrm{CN}-\mathrm{Na}$ between reflection and oxygen level. (d) Recovery efficiency of CN-K for different gases (0.258 vol\%). Inset: corresponding reflection spectra of different gases. (e) Cyclic recovery efficiency in the electrons released of consuming $\mathrm{O}_{2}(0.008,0.091$, and 0.258 vol\%). 
Thanks to the high reduction activity of accumulated photoelectrons and the excellent reversibility in color switching, $\mathrm{CN}-\mathrm{K}$ and $\mathrm{CN}-\mathrm{Na}$ were further applied as a colorimetric oxygen sensor. As depicted in Figure 4a, the reflection gradually increased as the oxygen level rose in the range of $0.008-0.25 \mathrm{vol} \%$, corresponding to the disappearance of the blue color of the system by naked eyes. The sensing mechanism was explored by the ESR analyses. Figure $\mathbf{4 b}$ and Figure $\mathbf{S 4}$ showed that $\mathrm{O}_{2} \bullet-$ was generated when molecular oxygen was introduced into the blue $\mathrm{CN}-\mathrm{K}$ or brown $\mathrm{CN}-\mathrm{Na}$ methanol suspension using 5,5-Dimethyl-1-pyrroline-N-oxide (DMPO) as the trapping agent. ${ }^{59-}$ ${ }^{61}$ It suggested that the target molecular oxygen consumed the photoelectrons from the CB and converted them into $\mathrm{O}_{2} \bullet-$, making the unique blue or brown color lighter. The calibration curve between reflection and oxygen concentration was plotted in Figure 4c. The limit of detection ( $\mathrm{LOD}, \mathrm{S} / \mathrm{N}=3$ ) for $\mathrm{CN}-\mathrm{K}$ was determined to be $0.002 \mathrm{vol} \%$, which was superior to the standard of the commercial oxygen sensor in gas (Table S2), and also comparable to that by fluorescence or UV-vis detection methods in previous reports (Table S3).

Interestingly, due to the more substantial photoelectron storage capacity, the $\mathrm{CN}-\mathrm{Na}$ colorimetric sensor exhibited a broader linear range for $\mathrm{O}_{2}$ detection $(0.08-8.33 \mathrm{vol} \%)$. It could be explained by the different nature of the physical and chemical pathways for photoelectrons accumulation, i.e., the former was faster, but the capacity was lower, while the latter was slower, but the capacity was higher. This correlation was like that between supercapacitors ${ }^{62}$ and secondary batteries ${ }^{63}$. Thus, by rational adjustment of $\mathrm{C} \equiv \mathrm{N}$ and $\mathrm{C}=\mathrm{O}$ defects in $\mathrm{CN}$, the $\mathrm{LOD}$ and the linear detection range could be fully engineered to adapt to different applications. As known, the concertation of analysts is quite different in a complex system, making the reliable detection a specific challenge by the traditional sensors that often have a fixed LOD and detection range. To our knowledge, such flexibly in sensor construction by $\mathrm{CN}$-derived photoelectron storage platforms was seldom reported in previous reports.

The potential interferences from other gases and organic molecules were evaluated under the same conditions. As shown in Figure 4c, only a trivial change in the 
discoloration rate was observed for the $\mathrm{CN}-\mathrm{K}$ sensor by interferences, such as $\mathrm{Ar}, \mathrm{N}_{2}$, ethanol, and $\mathrm{CO}_{2}$ at the same concentration of 0.25 vol\%. Nonetheless, slightly increased discoloration rates were found towards air and acetone, which were ascribed to the existence of oxygen molecules in the air $(21 \mathrm{vol} \%)$ and acetone $(6.79 \mathrm{mM})$ at $25^{\circ} \mathrm{C}$. In this sense, the $\mathrm{CN}$-derived colorimetric sensor demonstrated good selectivity in detecting oxygen molecules. Moreover, after discoloration, the proposed $\mathrm{CN}-\mathrm{K}$ and $\mathrm{CN}-\mathrm{Na}$ sensors could be recovered by irradiation. As shown in Figure 4d, upon the different oxygen concentrations, the $\mathrm{CN}-\mathrm{K}$ sensor demonstrated excellent reversibility and reproducibility in multiple measurements. This feature is highly envisioned, especially for less-developed regions or fieldwork, to improve the detection reliability and lower the sensing cost by multiple measurements.

In summary, we report functionalized carbon nitride, the raw materials-abundant and cheap semiconductors with photoelectron storage ability, can be developed as a new promising chromogenic system for colorimetric sensing. Beyond the traditional photoelectron storage materials that only demonstrated blue color in the excited state, $\mathrm{CN}$ with additional controllable brown color was obtained, thanks to its organic nature and multiformity. It was disclosed that cyano and carbonyl functional groups enabled a unique mixed physical and electrochemical process, like the working principle for capacitors and secondary batteries, which had fast and massive photoelectron storage, respectively. The DFT theoretical calculation further verified the critical role of cyano/carbonyl groups and the counter cations as well in elongating the centroids distance of electron and hole, which essentially inhibited the charge recombination and stabilized the long-lived excited state for $\mathrm{CN}$, the origin of the different color-switch before and after the irradiation. As a result, the $\mathrm{CN}$-derived colorimetric $\mathrm{O}_{2}$ sensors demonstrated not only excellent reversibility in recycling hundreds of times for detection but also adaptable limit of detection and linear detection range, superior to commercial $\mathrm{O}_{2}$ sensors, especially for complex systems with broad variable concentrations. Taking advantage of photoelectron storage, this work provides a new chromogenic platform for colorimetric sensing and highlights the great potential of 
semiconducting carbon nitrides with a tunable functional group in future sensing applications.

\section{References}

1. Schoolaert, E.; Hoogenboom, R.; De Clerck, K., Colorimetric Nanofibers as Optical Sensors. Advanced Functional Materials 2017, 27 (38), 1702646-1702672.

2. Wei, T.; Dong, T.; Wang, Z.; Bao, J.; Tu, W.; Dai, Z., Aggregation of Individual Sensing Units for Signal Accumulation: Conversion of Liquid-Phase Colorimetric Assay into Enhanced Surface-Tethered Electrochemical Analysis. Journal of the American Chemical Society 2015, 137 (28), 8880-8883.

3. Feng, C.; Mao, X.; Shi, H.; Bo, B.; Chen, X.; Chen, T.; Zhu, X.; Li, G., Detection of microRNA: A Point-of-Care Testing Method Based on a pH-Responsive and Highly Efficient Isothermal Amplification. Analytical Chemistry 2017, 89 (12), 6631-6636.

4. Chen, X.; Zhao, L.; Wu, K.; Yang, H.; Zhou, Q.; Xu, Y.; Zheng, Y.; Shen, Y.; Liu, S.; Zhang, Y., Bound oxygen-atom transfer endows peroxidase-mimic $\mathrm{M}-\mathrm{N}-\mathrm{C}$ with high substrate selectivity. Chemical Science 2021, 12 (25), 8865-8871.

5. Fu, G.; Sanjay, S. T.; Zhou, W.; Brekken, R. A.; Kirken, R. A.; Li, X., Exploration of Nanoparticle-Mediated Photothermal Effect of TMB- $\mathrm{H}_{2} \mathrm{O}_{2}$ Colorimetric System and Its Application in a Visual Quantitative Photothermal Immunoassay. Analytical Chemistry 2018, 90 (9), 5930-5937.

6. Chen, Z.; Wang, H.; Zhang, Z.; Chen, L., Chemical Redox-Cycling for Improving the Sensitivity of Colorimetric Enzyme-Linked Immunosorbent Assay. Analytical Chemistry 2018, 91 (2), 1254-1259.

7. Hammock, M. L.; Knopfmacher, O.; Ng, T. N.; Tok, J. B. H.; Bao, Z., Electronic Readout Enzyme-Linked Immunosorbent Assay with Organic Field-Effect Transistors as a Preeclampsia Prognostic. Advanced Materials 2014, 26 (35), 6138-6144.

8. Gao, Z.; Shao, S.; Gao, W.; Tang, D.; Tang, D.; Zou, S.; Kim, M. J.; Xia, X., Morphology-Invariant Metallic Nanoparticles with Tunable Plasmonic Properties. ACS Nano 2021, 15 (2), 2428-2438. 
9. Liu, L.; Gao, Z.; Jiang, B.; Bai, Y.; Wang, W.; Yin, Y., Reversible Assembly and

Dynamic Plasmonic Tuning of Ag Nanoparticles Enabled by Limited Ligand Protection. Nano Letters 2018, 18 (8), 5312-5318.

10. Nirmala, A.; Mukkatt, I.; Shankar, S.; Ajayaghosh, A., Thermochromic Color Switching to Temperature Controlled Volatile Memory and Counter Operations with Metal-Organic Complexes and Hybrid Gels. Angewandte Chemie International Edition 2020, 60 (1), 455-465.

11. Wu, J.; Kwon, B.; Liu, W.; Anslyn, E. V.; Wang, P.; Kim, J. S., Chromogenic/Fluorogenic Ensemble Chemosensing Systems. Chemical Reviews 2015, 115 (15), 7893-7943.

12. Zhang, H.; Li, Q.; Yang, Y.; Ji, X.; Sessler, J. L., Unlocking Chemically Encrypted Information Using Three Types of External Stimuli. Journal of the American Chemical Society 2021, 143 (44), 18635-18642.

13. Bedja, I.; Hotchandani, S.; Kamat, P. V., Photoelectrochemistry of Quantized $\mathrm{WO}_{3}$ Colloids: Electron Storage, Electrochromic, and Photoelectrochromic Effects. The Journal of Physical Chemistry 2002, 97 (42), 11064-11070.

14. Wang, P.; Chen, X.; Sun, G.; Wang, C.; Luo, J.; Yang, L.; Lv, J.; Yao, Y.; Luo, W.; Zou, Z., A Capacitor - type Faradaic Junction for Direct Solar Energy Conversion and Storage. Angewandte Chemie International Edition 2020, 133 (3), 1410-1415.

15. Kongkanand, A.; Kamat, P. V., Electron Storage in Single Wall Carbon Nanotubes. Fermi Level Equilibration in Semiconductor-SWCNT Suspensions. ACS Nano 2007, $1(1), 13-21$.

16. Peper, J. L.; Vinyard, D. J.; Brudvig, G. W.; Mayer, J. M., Slow Equilibration

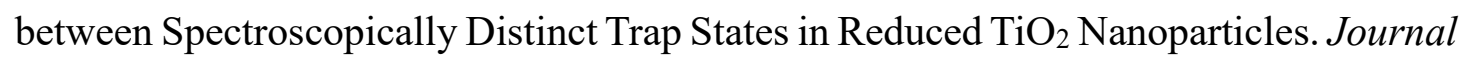
of the American Chemical Society 2017, 139 (8), 2868-2871.

17. Takai, A.; Kamat, P. V., Capture, Store, and Discharge. Shuttling Photogenerated Electrons across $\mathrm{TiO}_{2}-$ Silver Interface. ACS Nano 2011, 5 (9), 7369-7376.

18. Valdez, C. N.; Braten, M.; Soria, A.; Gamelin, D. R.; Mayer, J. M., Effect of Protons on the Redox Chemistry of Colloidal Zinc Oxide Nanocrystals. Journal of the 
American Chemical Society 2013, 135 (23), 8492-8495.

19. Podjaski, F.; Kröger, J.; Lotsch, B. V., Toward an Aqueous Solar Battery: Direct Electrochemical Storage of Solar Energy in Carbon Nitrides. Advanced Materials 2018, $30(9), 1705477-1705485$.

20. Podjaski, F.; Lotsch, B. V., Optoelectronics Meets Optoionics: Light Storing Carbon Nitrides and Beyond. Advanced Energy Materials 2020, 11 (4), 20030492003058.

21. Chen, G.; Zhang, Z.; Zhang, W.; Xia, L.; Nie, X.; Huang, W.; Wang, X.; Wang, L.; Hong, C.; Zhang, Z.; You, Y., Photopolymerization performed under dark conditions using long-stored electrons in carbon nitride. Materials Horizons 2021, 8 (7), 20182024.

22. Markushyna, Y.; Lamagni, P.; Teutloff, C.; Catalano, J.; Lock, N.; Zhang, G.; Antonietti, M.; Savateev, A., Green radicals of potassium poly(heptazine imide) using light and benzylamine. Journal of Materials Chemistry A 2019, 7 (43), 24771-24775.

23. Schrauben, J. N.; Hayoun, R.; Valdez, C. N.; Braten, M.; Fridley, L.; Mayer, J. M., Titanium and zinc oxide nanoparticles are proton-coupled electron transfer agents. Science 2012, 336 (6086), 1298-301.

24. Irie, M.; Lifka, T.; Uchida, K.; Kobatake, S.; Shindo, Y., Fatigue resistant properties of photochromic dithienylethenes: by-product formation. Chemical Communications 1999, (8), 747-750.

25. Matis, J. R.; Schönborn, J. B.; Saalfrank, P., A multi-reference study of the byproduct formation for a ring-closed dithienylethene photoswitch. Physical Chemistry Chemical Physics 2015, 17 (21), 14088-14095.

26. Schlomberg, H.; Kröger, J.; Savasci, G.; Terban, M. W.; Bette, S.; Moudrakovski, I.; Duppel, V.; Podjaski, F.; Siegel, R.; Senker, J.; Dinnebier, R. E.; Ochsenfeld, C.; Lotsch, B. V., Structural Insights into Poly(Heptazine Imides): A Light-Storing Carbon Nitride Material for Dark Photocatalysis. Chemistry of Materials 2019, 31 (18), 74787486.

27. Su, J.; Zou, X.; Li, B.; Chen, H.; Li, X.; Yu, Q.; Mi, Q.; Chen, J.-S., Accelerated 
room-temperature crystallization of ultrahigh-surface-area porous anatase titania by storing photogenerated electrons. Chemical Communications 2017, 53 (10), 1619-1621. 28. Savateev, A.; Markushyna, Y.; Schüßlbauer, C. M.; Ullrich, T.; Guldi, D. M.; Antonietti, M., Unkonventionelle Photokatalyse in leitfähigen Polymeren: Reversible Modulation der Leitfähigkeit von PEDOT:PSS durch langlebige Polyheptazinimid Radikale. Angewandte Chemie 2021, 133 (13), 7512-7520.

29. Cao, S.; Low, J.; Yu, J.; Jaroniec, M., Polymeric Photocatalysts Based on Graphitic Carbon Nitride. Advanced Materials 2015, 27 (13), 2150-2176.

30. Ji, J.; Wen, J.; Shen, Y.; Lv, Y.; Chen, Y.; Liu, S.; Ma, H.; Zhang, Y., Simultaneous Noncovalent Modification and Exfoliation of 2D Carbon Nitride for Enhanced Electrochemiluminescent Biosensing. Journal of the American Chemical Society 2017, 139 (34), 11698-11701.

31. Ou, H.; Tang, C.; Chen, X.; Zhou, M.; Wang, X., Solvated Electrons for Photochemistry Syntheses Using Conjugated Carbon Nitride Polymers. ACS Catalysis 2019, 9 (4), 2949-2955.

32. Savateev, A.; Dontsova, D.; Kurpil, B.; Antonietti, M., Highly crystalline poly(heptazine imides) by mechanochemical synthesis for photooxidation of various organic substrates using an intriguing electron acceptor - Elemental sulfur. Journal of Catalysis 2017, 350, 203-211.

33. Xiong, T.; Cen, W.; Zhang, Y.; Dong, F., Bridging the g-C3N4 Interlayers for Enhanced Photocatalysis. ACS Catalysis 2016, 6 (4), 2462-2472.

34. Zhang, G.; Liu, M.; Heil, T.; Zafeiratos, S.; Savateev, A.; Antonietti, M.; Wang, X., Electron Deficient Monomers that Optimize Nucleation and Enhance the Photocatalytic Redox Activity of Carbon Nitrides. Angewandte Chemie International Edition 2019, 58 (42), 14950-14954.

35. Savateev, A.; Pronkin, S.; Willinger, M. G.; Antonietti, M.; Dontsova, D., Towards Organic Zeolites and Inclusion Catalysts: Heptazine Imide Salts Can Exchange Metal Cations in the Solid State. Chemistry - An Asian Journal 2017, 12 (13), 1517-1522.

36. Savateev, A.; Pronkin, S.; Epping, J. D.; Willinger, M. G.; Wolff, C.; Neher, D.; 
Antonietti, M.; Dontsova, D., Potassium Poly(heptazine imides) from Aminotetrazoles: Shifting Band Gaps of Carbon Nitride-like Materials for More Efficient Solar Hydrogen and Oxygen Evolution. ChemCatChem 2017, 9 (1), 167-174.

37. Zhou, Z.; Shen, Y.; Li, Y.; Liu, A.; Liu, S.; Zhang, Y., Chemical Cleavage of Layered Carbon Nitride with Enhanced Photoluminescent Performances and Photoconduction. ACS Nano 2015, 9 (12), 12480-12487.

38. Krivtsov, I.; Mitoraj, D.; Adler, C.; Ilkaeva, M.; Sardo, M.; Mafra, L.; Neumann, C.; Turchanin, A.; Li, C.; Dietzek, B.; Leiter, R.; Biskupek, J.; Kaiser, U.; Im, C.; Kirchhoff, B.; Jacob, T.; Beranek, R., Water - Soluble Polymeric Carbon Nitride Colloidal Nanoparticles for Highly Selective Quasi - Homogeneous Photocatalysis. Angewandte Chemie 2019, 132 (1), 495-503.

39. Lau, V. W.-h.; Moudrakovski, I.; Botari, T.; Weinberger, S.; Mesch, M. B.; Duppel, V.; Senker, J.; Blum, V.; Lotsch, B. V., Rational design of carbon nitride photocatalysts by identification of cyanamide defects as catalytically relevant sites. Nature Communications 2016, 7 (1), 12165-12175.

40. Tian, J.; Zhang, L.; Wang, M.; Jin, X.; Zhou, Y.; Liu, J.; Shi, J., Remarkably enhanced $\mathrm{H}_{2}$ evolution activity of oxidized graphitic carbon nitride by an extremely facile $\mathrm{K}_{2} \mathrm{CO}_{3}$-activation approach. Applied Catalysis B: Environmental 2018, 232, $322-$ 329.

41. Yu, J.; Zhu, Z.; Zhang, H.; Shen, X.; Qiu, Y.; Yin, D.; Wang, S., Persistent free radicals on $\mathrm{N}$-doped hydrochar for degradation of endocrine disrupting compounds. Chemical Engineering Journal 2020, 398, 125538-125548.

42. Li, F.; Han, M.; Jin, Y.; Zhang, L.; Li, T.; Gao, Y.; Hu, C., Internal electric field construction on dual oxygen group-doped carbon nitride for enhanced photodegradation of pollutants under visible light irradiation. Applied Catalysis B: Environmental 2019, 256, 117705-117717.

43. Xia, J. L.; Yan, D.; Guo, L. P.; Dong, X. L.; Li, W. C.; Lu, A. H., Hard Carbon Nanosheets with Uniform Ultramicropores and Accessible Functional Groups Showing High Realistic Capacity and Superior Rate Performance for Sodium - Ion Storage. 
Advanced Materials 2020, 32 (21), 2000447-2000455.

44. Xia, P.; Antonietti, M.; Zhu, B.; Heil, T.; Yu, J.; Cao, S., Designing Defective Crystalline Carbon Nitride to Enable Selective $\mathrm{CO}_{2}$ Photoreduction in the Gas Phase. Advanced Functional Materials 2019, 29 (15), 1900093-1900102.

45. Dontsova, D.; Pronkin, S.; Wehle, M.; Chen, Z.; Fettkenhauer, C.; Clavel, G.; Antonietti, M., Triazoles: A New Class of Precursors for the Synthesis of Negatively Charged Carbon Nitride Derivatives. Chemistry of Materials 2015, 27 (15), 5170-5179. 46. Fang, Z.; Li, D.; Chen, R.; Huang, Y.; Luo, B.; Shi, W., Multiple Doped Carbon Nitrides with Accelerated Interfacial Charge/Mass Transportation for Boosting Photocatalytic Hydrogen Evolution. ACS Applied Materials \& Interfaces 2019, 11 (25), 22255-22263.

47. Xu, Y.; Qiu, C.; Fan, X.; Xiao, Y.; Zhang, G.; Yu, K.; Ju, H.; Ling, X.; Zhu, Y.; Su, C., $\mathrm{K}^{+}$-induced crystallization of polymeric carbon nitride to boost its photocatalytic activity for $\mathrm{H} 2$ evolution and hydrogenation of alkenes. Applied Catalysis B: Environmental 2020, 268, 118457-118464.

48. Xu, Y.; He, X.; Zhong, H.; Singh, D. J.; Zhang, L.; Wang, R., Solid salt confinement effect: An effective strategy to fabricate high crystalline polymer carbon nitride for enhanced photocatalytic hydrogen evolution. Applied Catalysis B: Environmental 2019, $246,349-355$.

49. Yu, H.; Shi, R.; Zhao, Y.; Bian, T.; Zhao, Y.; Zhou, C.; Waterhouse, G. I. N.; Wu, L.-Z.; Tung, C.-H.; Zhang, T., Alkali-Assisted Synthesis of Nitrogen Deficient Graphitic Carbon Nitride with Tunable Band Structures for Efficient Visible-LightDriven Hydrogen Evolution. Advanced Materials 2017, 29 (16), 1605148-1605155.

50. Wang, X.; Maeda, K.; Chen, X.; Takanabe, K.; Domen, K.; Hou, Y.; Fu, X.; Antonietti, M., Polymer Semiconductors for Artificial Photosynthesis: Hydrogen Evolution by Mesoporous Graphitic Carbon Nitride with Visible Light. Journal of the American Chemical Society 2009, 131 (5), 1680-1681.

51. Tan, H.; Gu, X.; Kong, P.; Lian, Z.; Li, B.; Zheng, Z., Cyano group modified carbon nitride with enhanced photoactivity for selective oxidation of benzylamine. Applied 
Catalysis B: Environmental 2019, 242, 67-75.

52. Wu, M.; Yan, J.-M.; Tang, X.-n.; Zhao, M.; Jiang, Q., Synthesis of PotassiumModified Graphitic Carbon Nitride with High Photocatalytic Activity for Hydrogen Evolution. ChemSusChem 2014, 7 (9), 2654-2658.

53. Chen, Z.; Savateev, A.; Pronkin, S.; Papaefthimiou, V.; Wolff, C.; Willinger, M. G.; Willinger, E.; Neher, D.; Antonietti, M.; Dontsova, D., "The Easier the Better" Preparation of Efficient Photocatalysts-Metastable Poly(heptazine imide) Salts. Advanced Materials 2017, 29 (32), 1700555-1700563.

54. Corp, K. L.; Schlenker, C. W., Ultrafast Spectroscopy Reveals Electron-Transfer Cascade That Improves Hydrogen Evolution with Carbon Nitride Photocatalysts. Journal of the American Chemical Society 2017, 139 (23), 7904-7912.

55. Zhang, G.; Li, G.; Heil, T.; Zafeiratos, S.; Lai, F.; Savateev, A.; Antonietti, M.; Wang, X., Tailoring the Grain Boundary Chemistry of Polymeric Carbon Nitride for Enhanced Solar Hydrogen Production and $\mathrm{CO}_{2}$ Reduction. Angewandte Chemie International Edition 2019, 131 (11), 3471-3475.

56. Lau, V. W.-h.; Klose, D.; Kasap, H.; Podjaski, F.; Pignié, M.-C.; Reisner, E.; Jeschke, G.; Lotsch, B. V., Dark Photocatalysis: Storage of Solar Energy in Carbon Nitride for Time-Delayed Hydrogen Generation. Angewandte Chemie International Edition 2017, 56 (2), 510-514.

57. Zhang, Y.; Mori, T.; Ye, J.; Antonietti, M., Phosphorus-Doped Carbon Nitride Solid: Enhanced Electrical Conductivity and Photocurrent Generation. Journal of the American Chemical Society 2010, 132 (18), 6294-6295.

58. Godin, R.; Wang, Y.; Zwijnenburg, M. A.; Tang, J.; Durrant, J. R., Time-Resolved Spectroscopic Investigation of Charge Trapping in Carbon Nitrides Photocatalysts for Hydrogen Generation. Journal of the American Chemical Society 2017, 139 (14), 52165224.

59. Lee, K. T.; Jung, Y. S.; Oh, S. M., Synthesis of Tin-Encapsulated Spherical Hollow Carbon for Anode Material in Lithium Secondary Batteries. Journal of the American Chemical Society 2003, 125 (19), 5652-5653. 
60. Li, P.; Li, J.; Feng, X.; Li, J.; Hao, Y.; Zhang, J.; Wang, H.; Yin, A.; Zhou, J.; Ma, X.; Wang, B., Metal-organic frameworks with photocatalytic bactericidal activity for integrated air cleaning. Nature Communications 2019, 10 (1), 2177-2187.

61. Wang, H.; Sun, X.; Li, D.; Zhang, X.; Chen, S.; Shao, W.; Tian, Y.; Xie, Y., Boosting Hot-Electron Generation: Exciton Dissociation at the Order-Disorder Interfaces in Polymeric Photocatalysts. Journal of the American Chemical Society 2017, 139 (6), 2468-2473.

62. Zhang, S.; Pan, N., Supercapacitors Performance Evaluation. Advanced Energy Materials 2015, 5 (6), 1401401-1401420.

63. Kim, H.; Han, B.; Choo, J.; Cho, J., Three-Dimensional Porous Silicon Particles for Use in High-Performance Lithium Secondary Batteries. Angewandte Chemie International Edition 2008, 47 (52), 10151-10154. 